\title{
WORKLIFE BALANCE AND EMPLOYEE PERFORMANCE IN THE NIGERIAN OIL AND GAS INDUSTRY
}

\author{
Bienwi-Patrick, Ledum \\ Department of Management, \\ University of Port Harcourt Business School
}

\author{
B. Chima Onuoha \\ Department of Management, \\ University of Port Harcourt.
}

\author{
Best C. Eke \\ Department of Management, \\ University of Port Harcourt
}

Article DOI: https://doi.org/10.36713/epra5284

\begin{abstract}
Based on the high rate of employee turnover, poor working organizational culture, and rising occupational imbalances in various workplace, the study examined work life balance and employee performance in selected oil and gas firms in Port Harcourt, Rivers State. The study adopts a descriptive survey design, the population of the study is 759 and the sample size is 262 using Taro Yamane's formula. 262 copies of structured questionnaire was distributed and completely filled and returned. Pearson product moment correlation and regression analysis was used to test the hypothesis. Cronbach alpha was used to test the reliability of the instrument. The study employed dimensions of worklife balance bordering around the leave policy of selected oil and gas firms and evaluated their influence on measures of employee performance such as; service delivery, efficiency and effectiveness. It was discovered that there is a significant positive relationship between leave policy and service delivery. The findings revealed that leave policy motivate employee ability to deliver services efficiently and effectively, in conclusion work life balance practice is an important factor in increasing employee performance. The researcher recommends that managers of these oil and gas firms should prioritize creating different work life balance incentives that will improve employee performance.
\end{abstract}

KEYWORDS: Worklife Balance, Employee Performance, Service Delivery, Oil and Gas firms

\section{INTRODUCTION}

Every employee is an integral part of the organization and its immediate society. In today's business world, employee performance is key determinant in the achievement of organizational goals. As a result, organizations look for different ways of motivating their employees, in order for them to give their best to the organization. Employee performance is a focal point in any establishment (Thevanes \& Mangaleswaran, 2018). Every policy should be geared towards increasing the employee performance. For organizations to remain on top they should be able to improve their employee performance and monitor it. In a situation where this does not occur, they are liable to face several challenges which stands as a set back to the organization in the sector where they belong (Mendis \& Weerakkody, 2017).

The line between work and life has been the subject of interest amongst scholars and practitioners nowadays. Several factors have been found to have sparked this interest and these include changes of demographic composition in the labor market and in the amount and pace of work, and increases in work hours (Kadnan, 2019), A person can live a life that is happy, healthy and successful when there is work-life Balance. Work-life Balance has indeed become a primary concern to those wishing to have good quality of life. Therefore, work life balance is a very important phenomenon that is of great concern to various employees in both private and public sector. It goes beyond prioritizing the work role and one's personal 
life. It also affects the social, psychological, economical and mental well-being of the individual. All these is been reflected in the output of the individual, which affects his or her performance in the work place on the long run. Work life balance has implication on employee attitudes, behaviours, wellbeing as well as organizational effectiveness (Obiageli, Uzochukwu, \& Ngozi, 2015). The competition for market leadership in the oil and gas industry, may lead to oil and gas firms' managers giving their employees excessive work load in order to meet up with their target. Employees try their best to be retained in the organization by putting in more time at work which may be at detriment of their personal life. All these may affect the upbringing of children, lead to broken and unhappy homes and poor social life.

According to Epie (2011), the Nigerian oil and gas industry is known for its long hour culture, and high work load of employees due to the dependence of the nation on revenue from this sector. They are most likely to be faced with issue of work life balance, due to the nature of the work environment. Policies are been made regarding work life balance, but its implementation has become an issue that needs to be looked into. Ensuring effective delivery of products and service to customers may be achieved by the ability of the management of these oil and gas firms to maintain policies that promote work life balance. Various anomalies in the form of kidnapping of expatriates, unhealthy turnover of contract staffs, poor benefits of contracts staffs etc. led to raised eye brows as to the employee work life balance within the industry. All these have led to managers having higher expectation of employees' performance at a poor compensational ground. It is most likely that there will be a misplacement of priority of interest by the employees trying to meet up with the target of the industry, which may affect their personal life. Hence, the study of work life balance and employee performance becomes imperative (Mulanya \& Kagiri, 2018).

The multi-faced demand between work and home responsibilities have assumed increased relevance for employees in oil and gas firms in recent years. This is due to demographic and workplace changes, such as; transformation in family structures, growing reluctance for 'long number of hours' acceptance culture, greater number of women in the workforce and technological advancement. All these may result in the employees having difficulty in prioritizing between their work roles and their personal lives. When oil and gas firms have a poor working organizational culture; such as buying of work-leave of employees, inconvenient period of leave for employees and the inability of employers to keep to leave policy in their employment agreement. All these may lead to stretched workloads which bring about different issues in the employee. These issue involves both the psychologically and the emotional well-being of employee and these action may result in reduction in employee performance such as, poor service delivery and health related issues (Thevanes \& Mangaleswaran, 2018).

Another major issue that may hinder employee performance are when work life balance incentives like, leave entitlement, flexi time, and family and welfare policies, are not adhered to by the management of these firms. These may lead some oil workers to work round the clock with little attention to themselves and their families, which may result to broken home and poor parental upbringing. The personal issues that employees of oil firms face outside work, may demoralize them and in turn discourage them to be zealous in their service delivery to customers. All these may result in customers threatening to withdraw their patronage from the firms. These are the issues that prompted this research investigation. The broad objective of the present study is to determine the extent to which work life balance affects employee performance in oil and gas firms in Port Harcourt, Rivers state. Specifically, the study is to determine the extent to which leave policy affects service delivery.

It is therefore hoped that the evidence from this study would serve as a crucial addition to the rising volume of knowledge on employee incentives and organizational citizenship behaviors, while also adding to the existing body of empirical literature in the underlying area of study for a developing nation like Nigeria.

\section{LITERATURE REVIEW}

To capture the theoretical, conceptual, and empirical framework of the underlying study, this section is presented as follows;

\subsection{Theoretical Framework \\ 2.1.1 Spill Over Theory}

The baseline line theory of this study is the spill over theory. The proponent of this theory is Guest (2002). It postulates the conditions under which spillover between the work micro system and the family micro system occurs. It can either positive or negative. If work- family interactions are rigidly structured in time and space, then spill over in term of time, energy and behavior is negative. When flexibility occurs which enables individuals to integrate and overlap work and family responsibilities in time and space lead to positive spill over which is instrumental in achieving healthy work life balance. According to Guest (2002), the determinants of work life balance are 
located in the work and home contexts. Contextual determinants include demands of work, culture of work, demands of home and culture of home. Individual determinants include work orientation (i.e. the extent to which work (or home) is a central life interest), personality, energy, personal control and coping, gender and age, life and career stage. The variables of the study are under the contextual determinants, which are leave policy and service delivery. The leave policy is the culture of work, while the service delivery is the demand of work(Mulanya \& Kagiri, 2018).

The nature of work life balance was defined both objectively and subjectively. The objective indicators include hours of work and hours of uncommitted or free time outside work. Subjective Indicators refer to the states of balance and imbalance. He also noted that balance may be reported when equal weight is given both to work and home or, when home or work dominates by choice. Spill over occurs when there is interference of one sphere of life with other. Also, numerous outcomes of work life balance which include personal satisfaction and wellbeing at work, home and life as a whole, performance at work and home, impact on others at work, family and friends.

The relevance of this theory to the study is that organizations are expected to adopt positive work life balance policies that will enable employee have a positive work life balance in which will make them be effectively committed to achieving the organization's goals (Kadnan, 2019).

\subsection{Conceptual Framework}

\subsubsection{The Concept of Work-life Balance}

The term work-life balance is commonly used as a more comprehensive expression to describe policies that have been previously termed 'family-friendly', but are now extended beyond the scope of the family. Work-life balance refers to the flexible working arrangements that allow both parents and non-parents to avail of working arrangements that provide a balance between work responsibilities and personal responsibilities (Redmond Valiulis and Drew, 2006).

The origin of work-life balance practices spans from work-life conflict experienced by employee. Work Life Conflict is the inter-role conflict that results when one's roles as an employee is incompatible with one other area such as being a spouse, parent or with other religious and leisure activities. The concept of Work Life Conflict recognises that most individuals have multiple roles. Work-life balance practices help minimise the amount of Work Life Conflict and also target the antecedents (Lero and Bardoel, 2007). Some of the antecedents' of work-life conflicts include heavy job demands and job overloads.
Work Life Balance proposed by Barrera (2007) would be adopted because it is broad and encompassing "Employers working constructively with their employees to put in place arrangements, which take into account the needs of the business as well as the non-work aspects of employees' lives" Barrera (2007). It comprise of both employees and employers who are both central to the subsequent use and successful implementation of Work Life Balance policies and practices. This can only be achieved as a joint effort between employers and employees.

A review of the work-life literature reveals that Work Life Balance initiatives can be broadly divided into four dominant categories which include flexible working arrangement (home working, compressed hours); leave arrangement (annual leave, Parental leave); dependent care assistance (Child care arrangements and Creche) and general services (Employment assistant programs) (De Cieri, Holmes, Abbott and Pettit, 2005; De Cieri and Bardoel, 2009). Work life balance are practices that are meant to help employees better manage their work and non-working times are called in the literature as work-family policies, family-friendly or family-responsive policies. In recent years, the term "work-life balance" has replaced what used to be known as "work-family balance" (Hudson Resourcing, 2005), there are other life activities that need to be balanced with employment may include study, travel, sport, voluntary work, personal development, leisure or eldercare. Work life balance in its broadest sense, is defined as a satisfactory level of involvement or 'fit' between the multiple roles in a person's life.

According to Clarke, Koch and Hill (2004), work-life balance is generally associated with equilibrium between the amount of time and effort somebody devotes to work and personal activities, in order to maintain an overall sense of harmony in life. To understand work-life balance, it is important to be aware of the different demands upon us and our personal resources- our time and our energy- that we can deploy to address them. Research has indicated that those workers who have some form of control over their working environment tend to suffer less stressrelated ill-health, with clear implications for the concept of work-life balance Organizations can implement various work-life balance initiatives that may assist employees to better balance their work and family responsibilities, gain improvements in wellbeing and provide organizational benefits. There are a large variety of family friendly policies which include, but are not limited to the following: flexible working hours, job sharing, part-time work, compressed work 
weeks, parental leave, telecommuting, on-site child care facility (Hartel, 2007).

Work life balance studies have significantly furthered our understanding of the phenomena; there remains great unevenness within Work Life Balance studies in a non-Western context.
In essence, while Work Life Balance in the West has received enormous research exposure, far less attention has been devoted to exploring the concept of Work Life Balance of individuals in Nigeria (Ojo 2014)

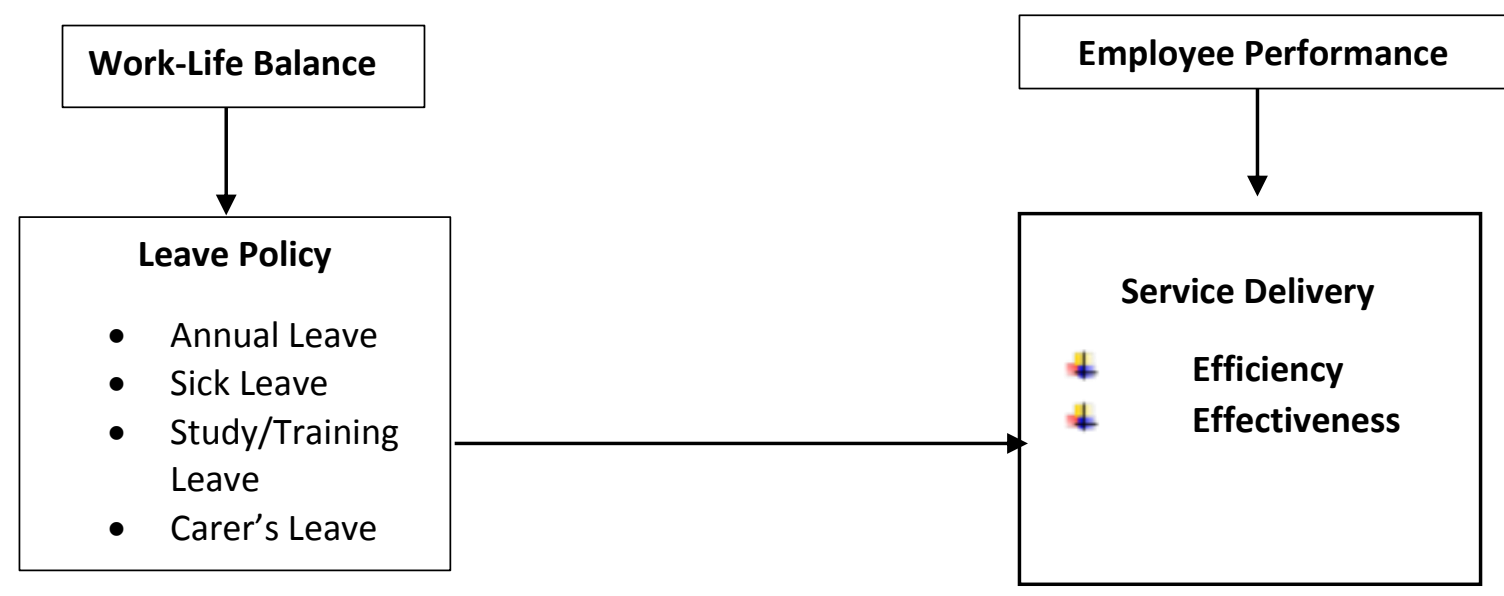

Figure 2.1: Conceptual Framework of Work-life balance and Employee

\subsubsection{Employee Performance}

Employee Performance in a firm is a very important area in the workplace. It can help the firm increase and utilize the capacity of the human resources it has. It translates into good service delivery and interaction in which affects every area of the organization. To achieve this organization need to make polices that will encourage employee performance. An employee's job performance depends on or is a consequence of some combination of ability, effort, and opportunity. But, the measurements can be done in terms of outcomes or results produced (Ferris et al., 1998). Performance is defined as the record of outcomes produced on a specified job function or activity during a specified time period. (Bernadrdin and Russel, 1998). According to this definition performance is set of outcomes produced during a certain time period. Hence the researchers have developed the working definition of employee performance for study purpose is that, "achievement of targets of the tasks assigned to employees within particular period of time". Performance is not only related to the action but also involves judgment and evaluation process (Ilgen and Schneider, 1991).

According to Campbell (1993) performance is related to that which the individual that is hired do in fulfilling his / her duties and the activities that can be examined and measurable are reflected. An organization needs high performance of its employees, so as to meet its goal and be able to achieve competitive advantage (Frese, 2002). According to business dictionary employee performance is the job related activities expected of a worker and how well those activities were executed. The organization success depends on the employee performance. Therefore, it is important for a manager to create a well -rounded approach to managing and coaching its workforce. The oil and gas firms are service industry and their main aim is to satisfy their customer. The service employee renders to the customer and employee performance is interrelated. When employees provide excellent customer service, they are exceeding job expectations. The popularity of an organization's service is based in part on the level of service received by the customer. For service industry the business is based almost solely on their employee's performance. That is why management must look for various ways in improving employee performance (Mulanya \& Kagiri, 2018).

\subsubsection{Leave Policy}

Leave is the amount of hours/days employees of an organization are permitted to be away from their employment position within a period of time without consequences. This time off is paid by the company and employees are allowed to request the time for any reason they wish to be off work. It also gives the ability for employee to release themselves from work stress and create a balance between work and their family activities. This type of work life balances helps employees to perform other duties outside work, which creates a balancing effect between work activities and 
life activities. There are different types of leave policy which are:

Annual leave: Annual leave can defined as paid leave for the purpose of recreation to which employees become entitled after a period of qualifying service or employment with a particular employer (Work Place Information, 2002).

Nigeria has been greatly influenced by the British system. The provisions of the Nigerian Labour Act (1974) mainly concern blue-collar workers and are very basic with limited government regulations for employers. Daily hours of work are to be fixed by mutual agreement or by collective bargaining between the employer and employee (section 13:1). Provision is made for rest intervals of no less than one hour in total if the day's work is longer than 6 hours (section 13,3), and for one day's rest per week (section 13:7). After twelve months of continuous service, a worker is entitled to an annual leave of at least six working days that may not be deferred by more than twelve months (section 18).

Parental Leave: Parental Leave is an official permission given to employees with child care giving responsibilities. Women are entitled to twelve weeks' maternity leave with at least half pay but usually the customary benefits are more generous with maternity leave fully paid. The female employees often times are the greater beneficiaries of this leave in Nigeria where maternity leave allows a nursing mother to be away from work for 3 months.

Carer's leave: Carer's leave is an official permission for an employee to take time off to takecare for an immediate family or household member who is sick or injured or help during a family emergence. But it comes out of the employee personal leave balance.

Paid Family and Medical leave: Paid Family and Medical leave relates with an officially granted leave of absence from work to attend to dependent care challenges or personal health concerns of the employee. Olumuyiwa Akinrole, Oludayo (2015)

Sick leave: Sick leave is time off from work that an employee can use to address their health and safety needs without losing pay.

Study leave: Study leave is given to any staff member who is undertaking an approved study course. Training leave is given to an employee for self-development and organization development.

\subsubsection{Service Delivery}

Service delivery indicates 'where', 'when' and 'how' the service product is delivered to the customer (Lovelock and Wirtz, 2004). The service delivery process can be broken down into service encounters that comprise the main part of the whole process (Danaher and Mattsson,
1994) and, as noted by Chowdhary and Prakash (2007), some generalization within service types is possible for different services and service providers, and managers may have to consider this in its design. Thus, the power to deliver optimal service quality will get the service firms competitive advantages among others in the same industry (Turel, Serenko \& Bontis, 2007). According lash (1999) to work life balance helps to enhance service delivery among the employees.

Service delivery is a component of business that defines the interaction between providers and clients where the provider offers a service, and it could be an information or task. In the oil and gas industry different types of services are being offered. The heads of the firm are located at one place. However, their branches are scattered and located across the country. The jobs of offering the services are assigned to employees and the performance on the job matters a lot. This is because it affects the customers' satisfaction, getting and retaining existing customers, complaints handling, targets achieved, sales turnover, profits, market shares and good will of the company. The performance of employees is important, not only in the oil and gas industry but other service sectors. Better performance gives satisfaction to the customers. Services are to be provided with minimum processing and waiting time, proper response, promptness and the desire to handle many customers as the demand arises (Mulanya \& Kagiri, 2018).

\subsection{Empirical Review}

A number of studies have been carried at that is related to work life balance.

Kadnan (2019) investigated the Relation of work-life balance, happiness, and employee performance, Accordingly, a questionnaire-based survey was designed to test the aforementioned model based on dataset of 289 employees' from the ( Med Pharma), Pharmaceutical industries in Jordan, Multiple regression was conducted to examined the research hypotheses. The results indicated that work-life balance and happiness positively and significantly affect employee performance. However, job satisfaction nonimpact in employee performance. The results have enormous implication for the Pharmaceutical industries sector in Jordan.

Thevanes and Mangaleswaran (2018) evaluated the relationship between work-life balance and job performance. In order to achieve the objectives, primary data were collected from 166 employees of selected private banks in Batticaloa region of Sri Lanka and the structured questionnaire was administered to collect the data. The data were analysed by using univariate and bivariate analyses. The findings of the 
study revealed that work-life balance has positive and significant relationship with job performance in overall. The current study is considered to be vital in understanding the empirical knowledge regarding the relationship between work-life balance and job performance.

Mulanya and Kagiri (2018) determine the extent to which work life balance affects employee performance. Specifically, the study determined the extent to which flexible work schedules, job sharing among employees, employee breaks and employee assistance programs affect employee performance in the organization. The study adopted descriptive survey and case study design and targets 68 employees of the Commission on Revenue Allocation. All the 68 employees of the target population were considered. The study found that the organization lacked effective flexible working arrangements that assisted in the performance improvement. Lack of flexible work schedule had reduced encouragement to continue performing well for the organization as well the employees' degreed of independence with their working arrangements. Successful job sharing arrangements served the needs both of individual employees and their work unit/departments. The commission did not encourage job sharing. There was a significance effect of employee breaks on employee performance. Employees felt re-energized and worked better after their annual leave. The employees were more committed because they were not denied any benefit because of taking leaves as demonstrated. There lacked effective employee assistance programs in the organization. The study recommended that the commission should establish effective flexible work schedules to enable employees attend to work and personal matters. There lacked adequate job sharing in the commission.

Mendis and Weerakkody (2017) undertook a research on the Sri Lankan telecommunication industry and recognize the impact of worklife balance on the employee performance. The target population of the research were executive level married employees in telecommunication industry in Sri Lanka. The study employed a sample size of 100 respondents The Data were analyzed through SPSS 15.0. The study reveal that there is a strong relationship between work life balance and employee performance, a strong relationship between work life balance and employee job satisfaction and a strong relationship between employee job satisfaction and employee performance. All these relationships are positive and have significant levels. The research findings give evidence that the better work life balance of the employees leads to increased employee performance and employee job satisfaction.

Sheppard (2016) investigated the contribution of worklife balance to employee performance in United States of America. Data were collected through semistructured interviews from a purposeful sample of 10 managers and 10 non-managerial employees working at a charter school organization in Harlem, New York. Data collection also included organizational performance track indicator documents on employee absenteeism, turnover, motivation, productivity, job satisfaction, and retention, archived organizational records on WLB programs, and current WLB programs and policies guidelines. Through methodological triangulation, a number of themes emerged. These themes included work-life balance programs' effectiveness, the importance of a supportive work environment, employee commitment and motivation, employee wellbeing and productivity, employee job satisfaction and quality work life, organizational culture change, and low utilization of the job sharing program. According to the study results, work-life balance programs could help improve organizational culture and employee overall performance. The results of this study may contribute to social change by preparing employers for success while simultaneously positioning individuals to attain optimum balance between work and life responsibilities.

Obiageli, Uzochukwu, and Ngozi (2015) evaluated the influence of worklife balance on employee performance in selected commercial banks in Lagos state. The research adopts a descriptive survey research design, the population of the study is 759 and the sample size is 262 using Taro Yamane's formula. 262 copies of structured questionnaire was distributed and completely filled and returned. Pearson product moment correlation and regression analysis was used to test the hypothesis. Cronbach alpha was used to test the reliability of the instrument. It was discovered that there is a significant positive relationship between leave policy and service delivery. The findings revealed that leave policy motivate employee ability to deliver services efficiently and effectively, in conclusion work life balance practice is an important factor in increasing employee performance. The researcher recommends that managers of these commercial banks should prioritize creating different work life balance incentives that will improve employee performance.

Typically Vishwa et al., (2015) investigated Empirical analysis of work life balance policies and its impact on employee's job satisfaction and performance. The aim of the research was to analyze the relationship between work life balance policies and employee job satisfaction. Questionnaire was filled by 
240 respondents who were used for the survey. The Statistical Package for Social Sciences (SPSS) was used to analyze the quantitative data using correlation. The findings of this study emphasized that each of the work life balance policies on its own is a predictor of job satisfaction.

Mendis and Weerakkody (2014) carried out research on the Sri Lankan telecommunication industry and recognized the impact of work life balance on the employee performance. And also to identify whether the work life balance leads to higher employee performance (EP) through employee job satisfaction. The target population of this research is executive level married employees in telecommunication industry in Sri Lanka. This investigation area is used Cluster sampling method to select 2 major companies in telecommunication industry. (Dialog Axiata PLC and Sri Lanka Telecom - Sample Size 100) Data were gathered through questionnaire method and in this study, for the purpose of hypothesis testing the researcher use univariate, bivariate and multivariate statistics methods. The Data were analyzed through SPSS 20.0 software to find out the relationship between variables Based on the empirical investigation of the research the researcher can conclude that there is a strong relationship between work life balance and employee performance, a strong relationship between work life balance and employee job satisfaction and a strong relationship between employee job satisfaction and employee performance. All these relationships are positive and have significant levels.

Azeem and Akhtar (2014) investigated the influence of work life balance and job satisfaction on organization commitment of health care employee. This was aimed at exploring the influence of work life balance and job satisfaction has on organization commitment among healthcare employee. Questionnaire was distributed to 275 respondents in the healthcare sector. The Statistical Package for Social Sciences (SPSS) was used to analyze the quantitative data including correlation and reliabilities. The finding of the empirical test shows that employee in the health care sector have a moderate level of perceived work life balance, job satisfaction and commitment. There is a positive relationship between work life balance, job satisfaction and organization commitment.

Ojo, Salau and Falola (2014) investigated the concept of work-life balance policies and practices in three sectors of the Nigerian Economy namely the Banking, Educational and Power Sector. The types of Work Life Balance initiatives available in the three sectors were explored and the barriers to implementation of the Work Life Balance initiatives were identified. Quantitative method was used to investigate the work-life balance practices in three sectors of the Nigerian Economy. This was achieved using an in-depth case study analysis of these sectors. The data set comprised of responses from both managers and employees in the Oil and gas industry with five hundred and eighty six copies of the questionnaire retrieved. The Educational sector comprised of both managers and employees with five hundred and thirty one copies of the questionnaire retrieved; while five hundred and seven copies retrieved from the Power Sector. The findings reveal that there is diversity in terms of how respondents perceive the concept of Work-Life Balance. The Statistical Package for Social Sciences (SPSS) was used to analyze the quantitative data including Anova .There is a wide gap between corporate Work Life Balance practices and employees' understanding of the concept; the paper suggests some policy implications which would aid the implementation of Work Life Balance policies in the studied sectors.

Fapohunda (2014) investigated on the exploration of the effect of work life balance on productivity. The aim of the study was to explore the connection between work life balance and organization productivity and whether work life balance practice possibly decreases employee turnover and absenteeism. 200 respondents in the banking industry were used for the survey. A structured questionnaire was used to collect data. Chi square was used to analyze the data. The finding of the result was that there is a positive relationship between work life balance practice and employee turnover. It also found out that management support was not satisfactory.

Kamau, Muleke, Makaya and Wagoki, (2013) investigated work life balance practices on employee job performance at eco bank Kenya. The main objective was to determine the effect of organization work life balance on employee performance. Fifty-Five (55) Eco Bank employees were drawn through quota sampling method who also responded to survey questionnaires. Spearman's Correlation Analysis was used to test the candidates' work life balance, their performance to the organization. The finding of the empirical study shows that there was correlation between work life balance and employee performance. Typically, Hye

(2013) investigated "the work life balance and employees performance: the mediating role of affective commitment" which was aimed at investigating the effect of work life balance on affective commitment and in role performance. 293 respondents filled the questionnaires which were used for the survey. The Statistical Package for Social Sciences (SPSS) was used to analyze the quantitative 
data including reliabilities and multiple regressions. The finding of the empirical test demonstrated that employee experience of work life balance increase affective commitment.

Dissanayaka and Ali (2013) investigated the impact of work life balance on employee performance. The aim of the study was to analyze the relationship between work life balance and employee performance. 96 employees were used for the survey and questionnaire was distributed to them in which the data was used to run analysis. Pearson moment correlation was used to analyze the data. The finding of the result was that there is a positive relationship between work life balance and employee performance. Also there is a need for systematic effort to enhance work life balance of the employee to achieve better employee performance.

Ojo (2012) investigated work life balance practices and policies manager and employee experience in Nigeria oil and gas industry. The aim of the research is to explore the extent to which work life balance policies/ practices in organization in Nigeria. Questionnaire was used as the instrument and 600 respondents were used for the survey. Spearman's correlation analysis was used to analyze the data. The finding of the empirical study shows that there is need to enlighten employee about the various work life balance. Sakthivel, Kamalanabhanb and Selvarania (2011) investigated work life balance reflections on employee satisfaction. The aim of the research was to analyze the relationship between employee satisfaction and work/life balance. The construct used for this research consists of career opportunity, recognition, work tasks, payments, benefits, superior subordinate relationship, employee satisfaction, and work/life balance. Questionnaire was filled by 210 respondents working in IT organization. The Statistical Package for
Social Sciences (SPSS) was used to analyze the quantitative data including multiple correlation and regression. Findings of the empirical test show that high correlation exists between work task and employee satisfaction with a mediator variable namely work-life balance.

Similarly, Simonetta and Manfred (2010) looked at "work life balance which was an audit of staff experience at oxford Brookes University" investigated the significance of work life practice for the university. They looked at the various work life balances practices in the university and how they were utilised by staff of the university. The sample included 492 staff of the oxford brooks university. The finding shows that it is important to achieve a balance between paid work and personal life and that this enables them to work better. The staff agreed that for this to be achieved it is a joint responsibility between the employers and the employee. There are limited research on the use and availability of work-life balance practices and the implementation of these programmes in developing countries. There remains much to learn about Nigeria and how best to support their capacities to support employees' work-life balance, especially for arrangement of leave during a time of increased economic pressure it is this gap in knowledge that research seeks to fill.

\section{METHODOLOGY}

The study employed the descriptive survey method. This method was used because it gives greater room to study the subject matter and ensures that inferences can be made about some characteristic attitude or behavior of the population in the study. To achieve a research - oriented work the researcher delimited the work to the employees in the publicly listed oil and gas firms;

Table 3.1 Population size of downstream petroleum firms

\begin{tabular}{l|l} 
S/NO & Downstream Oil and Gas Firms \\
\hline 01 & 11 Plc. \\
02 & Anino International Plc. \\
03 & Capital Oil Plc. \\
04 & Eterna Plc. \\
05 & Forte Oil Plc. \\
06 & Japaul Oil \& Maritime Servives Plc. \\
07 & MRS Oil Nigeria Plc. \\
08 & Oando Plc. \\
09 & Rak Unity Petroleum Company Plc \\
10 & Conoil Plc. \\
11 & Shell Petroleum Development Company Ltd. \\
13 & Total Nigeria Plc. \\
Source: NSE 2019 &
\end{tabular}


Based on Table 3.1, the study accessible population will comprise of the managerial and nonmanagerial staff located in Port Harcourt, Rivers State. The managerial staff comprise of the heads of various department, while the non-managerial staff comprise of employees of the operation department and marketing department.

The population of this study is employees of the Port Harcourt branches of theses firms. Therefore, the estimated assessable population under consideration is 759. The sample size is two hundred and sixty two (262). It is obtained from the population unit (759) using Yamane's Statistical Distribution Formula. The sampling technique for the participant selection was judgmental sampling. Bowley population allocation formula $(\mathrm{nNh} / \mathrm{N}$, where $\mathrm{n}=$ Sample size, $\mathrm{Nh}=$ Population of each organization, $\mathrm{N}=$ Total Population) was used to determine the number of participant to be drawn from each organization. Due to the nature of the Study, only three of the stipulated firms were visited by the researcher i.e. Total Nigeria Plc (93), Conoil Plc (90), and Shell Petroleum Development Company of Nigeria Limited (79). This method gave the population equal chance of being included in the research study. Questionnaire structured into two sections was used to collect data for analysis. it comprises of two parts which are; leave policy and service delivery which has six (6) Items each. 5-point likert Scale, weighted; 1- 5: Strongly Disagree (SD), Disagree (D), Undecided (UD) Agree (A) and Strongly Agree (SA).

The validity of the instrument was ascertained by giving out copies of the draft questionnaire, research questions, hypothesis, alongside with the purposes of the study to expert. They were asked to check the face and content validity of the instrument to see if the instrument will actually measure what it intends to measure. Cronbach's coefficient alpha was used to determine the internal consistency and reliability of the multiple item scales.

\begin{tabular}{|ccc|}
\hline \multicolumn{1}{|c}{ Table 1: Cronbach's Alpha Reliability Statistics } \\
\hline Cronbach Alpha & Cronbach Alpha based on standardised items & No. of items \\
\hline 964 & 0.967 & 12 \\
\hline
\end{tabular}

The alpha value for the construct indicates that the items that formed them had reasonable internal consistency reliability of 0.967 . Hence the instrument is considered appropriate for the study (George and Mallery, 2003). This implies that the questionnaire is valid for measuring the relationship between leave policy and service delivery.

\section{RESULTS AND DISCUSSIONS}

Descriptive statistics such as frequencies and percentages will be used in answering the research question. . This hypothesis is tested using the Product Moment Pearson Correlation Coefficient (r) to find the positive relationship between Leave Policy and Employee performance in Nigerian oil and gas firms. The Pearson's correlation coefficient $r$ measures the strength and direction of a linear relationship between two variables. All the 262 copies of questionnaire distributed were properly completed and returned. Thus, the return rate is $100 \%$. Therefore, the 262 respondents that participated in the study were used in the analyses.

Table 4.1: Characteristics of the Respondents

\begin{tabular}{|llcc|}
\hline SN & Variables & Frequency & $\begin{array}{c}\text { Percentage } \\
(\%)\end{array}$ \\
\hline 1 & Sex & 143 & 54.6 \\
& Male & & \\
& Female & 119 & 45.4 \\
& Total & 262 & 100 \\
\hline 2 & Age & 37 & 14.1 \\
& 23 to 30 years & 80 & 30.5 \\
& 31 to 38 years & 115 & 43.9 \\
& 39 to 45 years Above 45 years & 30 & 11.5 \\
& Total & 262 & 100 \\
\hline 3 & Experience & 28 & 10.7 \\
& 1 to 10 years & 74 & 28.2 \\
& & &
\end{tabular}




\begin{tabular}{lcc|}
11 to 20 years & 121 & 46.2 \\
21 to 30 years 31 to 35 years & 39 & 14.9 \\
Total & 262 & 100 \\
\hline
\end{tabular}

Sex/gender distribution of the respondents indicate that 143 males and 119 females representing $54.6 \%$ and $45.4 \%$ respectively, were involved in the study. The results show that males are $9 \%$ more than the female respondents. The results also indicated that persons between the ages of 23 to 30 years are 37 $(14.12 \%)$, those between the ages of 31 to 38 years are $80(30.53 \%)$. Again, the number of persons between the ages of 39 to 45 years is $115(43.89 \%)$ and those above 45 years of age are $30(11.45 \%)$. The result indicate that the work force in the oil and gas firms cluster around persons between the ages of 31 to 45 , with those between the ages of 39 to 45 having the highest number.

For years of experience, the results indicate that persons who have worked in the oil and gas firms between 1 to 10 years are $28(10.69 \%)$, those who have worked between 11 to 20 years are $74(28.24 \%)$, while those between 21 to 30 years are 121 (46.18\%). However, those who worked between 31 to 35 years are $39(14.89 \%)$ persons. The analysis indicate that majority of the respondents have adequate experience in the organization. This means that they understands the work conditions of the organization and thus are suitable for the study.

Table 4.2: Responses on Application of Leave Policy in the Organizations

\begin{tabular}{|c|c|c|c|c|c|c|c|}
\hline SN & Variables & $S A$ & $A$ & $U$ & $D$ & $S D$ & Remarks \\
\hline 1 & $\begin{array}{l}\text { My organization give me leave to } \\
\text { care and support my dependents }\end{array}$ & $\begin{array}{c}52 \\
(19.80 \%)\end{array}$ & $\begin{array}{c}106 \\
(40.50 \%)\end{array}$ & $\begin{array}{c}50 \\
(19.10 \%)\end{array}$ & $\begin{array}{c}44 \\
(16.80 \%)\end{array}$ & $\begin{array}{c}10 \\
(3.80 \%)\end{array}$ & Agree \\
\hline 2 & $\begin{array}{l}\text { My organization observes the } \\
\text { leave policy in the employment } \\
\text { agreement. }\end{array}$ & $\begin{array}{c}50 \\
(19.10 \%)\end{array}$ & $\begin{array}{c}101 \\
(38.50 \%)\end{array}$ & $\begin{array}{c}55 \\
(20.00 \%)\end{array}$ & $\begin{array}{c}45 \\
(17.20 \%)\end{array}$ & $\begin{array}{c}11 \\
(4.20 \%)\end{array}$ & Agree \\
\hline 3 & $\begin{array}{l}\text { Sick leave helps me to take care of } \\
\text { my emotional health }\end{array}$ & $\begin{array}{c}54 \\
(20.60 \%)\end{array}$ & $\begin{array}{c}110 \\
(42.00 \%)\end{array}$ & $\begin{array}{c}49 \\
(18.70 \%)\end{array}$ & $\begin{array}{c}39 \\
(14.90 \%)\end{array}$ & $\begin{array}{c}10 \\
(3.80 \%)\end{array}$ & Agree \\
\hline 4 & $\begin{array}{l}\text { Study/training leave allows me to } \\
\text { take time off for study or training } \\
\text { to improve on my personal } \\
\text { growth }\end{array}$ & $\begin{array}{c}46 \\
(17.60 \%)\end{array}$ & $\begin{array}{c}115 \\
(43.90 \%)\end{array}$ & $\begin{array}{c}50 \\
(19.10 \%)\end{array}$ & $\begin{array}{c}42 \\
(16.00 \%)\end{array}$ & $\begin{array}{c}9 \\
(3.40 \%)\end{array}$ & Agree \\
\hline 5 & $\begin{array}{l}\text { Annual leave helps me to reduce } \\
\text { work related stress }\end{array}$ & $\begin{array}{c}51 \\
(19.50 \%)\end{array}$ & $\begin{array}{c}102 \\
(38.90 \%)\end{array}$ & $\begin{array}{c}52 \\
(19.80 \%)\end{array}$ & $\begin{array}{c}45 \\
(17.20 \%)\end{array}$ & $\begin{array}{c}12 \\
(4.60 \%)\end{array}$ & Agree \\
\hline 6 & $\begin{array}{l}\text { My firm usually gives me } \\
\text { additional leave to complete my } \\
\text { annual leave. }\end{array}$ & $\begin{array}{c}52 \\
(18.80 \%)\end{array}$ & $\begin{array}{c}105 \\
(40.10 \%)\end{array}$ & $\begin{array}{c}51 \\
(19.50 \%)\end{array}$ & $\begin{array}{c}44 \\
(16.80 \%)\end{array}$ & $\begin{array}{c}10 \\
(3.80 \%)\end{array}$ & Agree \\
\hline & Mean percentage response & $19.23 \%$ & $40.65 \%$ & $19.37 \%$ & $16.48 \%$ & $3.93 \%$ & Agree \\
\hline
\end{tabular}

Key: SA = Strongly Agree, A = Agree, U = Undecided, D = Disagree, SD = Strongly Disagree Source: Survey data 2015, computation from SPSS 20 Analysis

The analyses on the table above answers whether there is implementation of Leave in the oil and gas industry. The responses are structured from strongly agree to strongly disagree. From the results, highest frequencies of the responses in each of the question items are the Agree Option. This means that most of the respondents generally agree that leave policy is implemented in the oil and gas firms. This implies that organizations under study (the oil and gas industry) grants employee leaves. 
Table 4.3: Responses on Level of Service Delivery Resulting from Leave Policy

$\begin{array}{lllllllll}S N & \text { Variables } & S A & A & U & D & S D & \text { Remarks }\end{array}$

\begin{tabular}{l|l}
7 & My work gives me time to attend
\end{tabular} to my family

8 I normally feel efficient each time I return from a leave

9 I feel motivated to render more services to my organization after the leave

10 My boss only allows me leave when s/he feels I do not have unfinished work on my table

11 My company's leave policy enables me to take care of my personal life while remaining efficient.

12 My family life does not affect my job efficiency.

Mean percentage response
52

$(19.80 \%)$

53

(20.20\%)

\author{
52
}

(19.80\%)

105

(40.10\%)

51

50
$(19.10 \%)$

46
$(17.60 \%)$

10

(3.80\%)

39

(14.90\%)

117

(44.70\%)

50
$(19.10 \%)$

44
$(16.80 \%)$

50
$(19.10 \%)$

(16.80\%)

11

(4.20\%)

$\begin{array}{cccccc}45 & 104 & 53 & 43 & 17 & \text { Agree } \\ (17.20 \%) & (39.70 \%) & (20.20 \%) & (16.40 \%) & (6.50 \%) & \end{array}$

$\begin{array}{cccccc}65 & 98 & 45 & 46 & 8 & \text { Agree } \\ (24.80 \%) & (37.40 \%) & (17.20 \%) & (17.60 \%) & (3.10 \%) & \\ 19.45 & 40.21 \%) & 19.03 \%) & 16.87 \%) & 4.45 \%) & \text { Agree }\end{array}$

SA = Strongly Agree, A = Agree, $\mathrm{U}=$ Undecided, D = Disagree, SD = Strongly Disagree Source: Survey data 2015, computation from SPSS 20 Analysis

The table above shows that opinion of the firm employees with regards to their service delivery after Leave grants. The overall responses as shown in the mean percentage response indicate that $19.45 \%$ of the respondents answer Strongly Agree, 40.21\% answers Agree, 19.03\% answers Undecided, while 16.87\% and $4.45 \%$ answers Disagree and Strongly Disagree Hypothesis Test

Hypothesis: There is a positive relationship between leave policy and employee service delivery. Correlations

Table 4.4: Correlation Analyses Cumulative Leave Policies and Service Delivery

\begin{tabular}{l|lcc}
\multicolumn{2}{l}{ LEAVE POLICIES } & SERVICE \\
\hline \multirow{2}{*}{ LEAVE POLICIES } & Pearson Correlation & 1 & Delivery \\
& Sig. (2-tailed) & & $.998^{* *}$ \\
SERVICE DELIVERY & $\mathrm{N}$ & 22 & 0 \\
& Pearson Correlation & $.998^{* *}$ & 22 \\
& Sig. (2-tailed) & 0 & 1 \\
& $\mathrm{~N}$ & 22 & 22
\end{tabular}

**. Correlation is significant at the 0.01 level (2-tailed).

Source: SPSS version 25 Output respectively. The analysis indicates that majority of the respondent answers Agree. This means that there is a general agreement that service delivery can relate to the organization's leave policy. 
The result, the Coefficient of Correlation (r) is 0.998. Based on the decision rule, there is strong positive correlation between Leave Policies and Service Delivery. The significance level is 0.000 which is below $0.05(\mathrm{p}<0.05)$. Based on the decision rule for significant level, we reject the null hypothesis. Therefore, we conclude that "There is a positive relationship between oil and gas firms' leave policies and service delivery"

This means that as the extent of implementation of Leave Policy have positive effect on the level of employee efficiency in service delivery This implies that organizations that implement leave policy tend to motivate their employee to be more efficient in service delivery.

\section{Discussion of Findings}

The finding from the work revealed gender distribution of the respondents indicate that representing $54.6 \%$ representing male and $45.4 \%$ female respectively, were involved in the study. That means that work life balance affect both the genders in the work force. Every individual is involved in issue that requires him/her prioritizing work role and personal commitment which is in line with the assertion of Ojo (2012). It also revealed that leave policy is implemented in the oil and gas industry but there is more room for improvement. The findings from this work revealed that there is a strong positive relationship between leave policy and service delivery. Leave policy also goes a long way in motivating employee to be more efficient in their duties. For an employee to remain productive in the organization, the organization must continue to improve on their work life balance incentives. This will produce an employee that will be more effective and efficient in delivery of services to the customer. This study has shown that work life balance is an important factor that brings about employee performance. The employee is productive by his ability to render a "come back again services" to their customer and this is achieved when employee are motivated by the various leave policy given to them by the organization. Ojo (2012); Dissanayaka and Ali (2013); Kamau, et al., (2013); Hye (2013); Ojo et al., (2014); Azeem and Akhtar (2014) and Vishwa et al., (2015) supported the finding that there is a positive relationship between work life balance and employee performance.

\section{CONCLUSION AND RECOMMENDATIONS}

Conclusion: This study concludes that work-life balance philosophy is associated with employee performance. This is because the social and psychological life of every employee needs to be rightly put in check for them to be an asset and not just an employee that is used to carry out day to day operations of the organisation. In line with vans cotter (2000) high employee performance lead an organization to have greater opportunities for employees than those who have low performance. Therefore it is important for employer to look for better ways in improving employee performance. This can be done by helping them prioritize their work and life activities. When this is achieved, employee is motivated to render their service efficiently and effectively

Employees are happier when they are able to balance their work life demands. Management also experience improve relationship with employees. Management support for employees work life balance fosters a good relationship between the work force and management which improve effective communication in the organization.

\section{Recommendations}

On the basis of the findings and conclusion drawn from the study, the following recommendations were made.

* The management of the Oil and gas firms should make sure they strategies different work life incentive that will encourage the employees to be more productive on their job.

* Also, managers of these organisations should encourage their employee to fix their leave at their convenient period after performing all their work related duties.

* Managers of these organisations should create activities that improve employee leisure time. Sport activities

* Management should create forum for get together between employee and their family and award ceremonies in which their immediate family will be involved.

* Management of oil and gas firms should create child care assistance this will help the employee. Which are creche services, day nursery and after school childcare.

* Provision of family welfare policies to encourage care for dependent.

\section{REFERENCES}

1. Arrangements on Work-life Conflict and Work Pressure in Ireland", Gender, Work and Organization, 16, 73-97.

2. Azeem, S.A., \& Akhtar, N. (2014). The influence of work life balance and job satisfaction on organizational commitment of healthcare employees'. International journal of Human Resource Studies, 4(2), 18-24. 
3. Benardin, H. I \& Rusell, J. E. (1998) Human resource management: an experimental approach. $2^{\text {nd }}$ ed. Irwin: McGraw Hill.

4. Business Dictionary Definitions. (2012). Retrieved from

http://www.businessdictionary.com/definition/produ ctivity.html Business dictionary definitions (2015). Retrieved from

5. Clarke, M., Koch, L., \& Hill, E. (2004), "The workfamily interface: Differentiating balance and fit", Family and Consumer Sciences Research Journal, 33(2), 121-140.

6. De Cieri, H., \& Bardoel, E. A. (2009). What does "work-life management" mean in China and Southeast Asia for MNCs? Community, Work and Family, 12(2), 179-196. http://dx.doi. org/10.1080/13668800902778959

7. Dissanaya. $M$ \& Hussain, A. (2013) Impact of work life balance on employees performance an empirical study on seven apparel organization in Sri lanka. Proceedings of the third International Symposium

8. Experience in the Nigerian Oil and gas industry. Brunel Business School - Doctoral Symposium 27th \& 28th March.

9. Factors affect productivity. (2012). Retrieved from http://www.nbrii.com/employeesurvey- whitepapers/5-factors-that-affect-your-employeesproductivity.

10. Fapohunda, T. M. (2014). An exploration of the effects of work life balance on productivity. Journal of Human Resource Management and Labour Studies, 2(2) 71-89.

11. Golden, L. (2012). The effects of working time on productivity and firm performance. A Research Synthesis Paper: International Labour Organization, Geneva.

12. Guest, D. E. (2002). Human resource management: When research confronts theory. International Journal of Human Resource Management, 12(2), 22-38.

13. Hudson Resourcing. (2005). The case for work/life balance: Closing the gap between policy and practice. Hudson Australia and New Zealand available on www.hudson.com

14. Hye, K. K. (2014) work life balance and employee performance. The mediating role of affective commitment. Global Business Management Research: An International Journal, 6(1), 37-51.

15. Ikeanyibe, O. M. (2009) Principles and practices of public personnel administration: A Nigeria perspective. Onitsha: Perfect Image.

16. Kadnan, B. K. (2019). Impact of work-life balance, happiness at work, on employee performance. International Business Research, 12(2), 99-112.

17. Kamau, J. M, Muleke V, Makaya S. O, \& Wagoki, $J$. (2013) Work life balance practices on employee performance of Ecobank Kenya. European journal business and management, 5(25), 179-185.
18. Kartzell, R. \& Yanalorich, G. (2000). Work Productivity and Job Satisfaction. New York, university press New York

19. Lasch, E. (1999). Achieving a Balance, Ohio Certified Public Accounts Journal, 58(1): 2122.

20. Laschinger, H, Fineganj. \& Shamain J. (2001). 'The impact of workplace empowerment and org trust on staff nurses work satisfaction and organization commitment. Health Care Management Review, 26, 7-23.

21. Lee, C. M., Elke, D. \& Dobson, R. D. (2009) 'Work-life balance for early career canadian psychologists in professional programs Canadian psychology'. Canadian Psychological Association, $50(2), 73-82$

22. Lero, D. S. \& Bardoel, A. (2009). Including the social-cultural and policy contexts in our multilevel, Multi-National study of work-family conflict. Report to the International Workshop. Guelph, ON.

23. Lewis, S., Rapoport, R. \& Gambles, R. (2007). The constraints of a work life balance approach: An international perspective. The International Journal of Human Resource, 18(3), 360 - 373.

24. Maertz, C. P., \& Boyar, S L. (2009) 'Work-Family Conflict, Enrichment, and Balance under "Levels" and "Episodes Approaches'. Journal of Management, 37(1), 68-98.

25. McPherson, M., \& Reed, P. (2007) Work-life balance in the New Zealand context, in Waring, M., \& Fouche, C. Managing mayhem: Work-life balance in New Zealand. Wellington, New Zealand: Dumoure Publishing Ltd.

26. Mendis, M. D. V. S., \& Weerakkody, W. A. S. (2014). The relationship between work life balance and employee performance: With reference to telecommunication industry of Sri Lanka. Kelaniya journal of human resource management, 9(1-2).

27. Mendis, M. D. V. S., \& Weerakkody, W. A. S. (2017). The impact of work life balance on employee performance with reference to telecommunication industry in Sri Lanka: a mediation model. Kelaniya Journal of Human Resource Management, 12(1), 72-100.

28. Mulanya, C., \& Kagiri, A. (2018). Effect of Work Life Balance on Employee Performance in Constitutional Commissions in Kenya.The Strategic Journal of Business and Change Management, 5(4), 1448-1466.

29. Obiageli, O. L., Uzochukwu, O. C., \& Ngozi, C. D. (2015). Work-life balance and employee performance in selected commercial banks in Lagos State. European Journal of Research and Reflection in Management Sciences, 3 (4), 63, 77.

30. Ojo, .I. S., Falola, H. O \& Mordi, C. (2014) Work life balance policies and practices: A case study of Nigerian female university students. European Journal of Business and Management 6 (12), 184193

31. Ojo, I. S., Salau, O. P., \& Falola, H. O. (2014) work life balance practices in Nigeria a 
comparison of three sector journal on competitiveness. Journal of competiveness 6(2),314. DOI: 10.7441/joc.2014.02.01

32. Ojo, S. (2012) Work Life Balance Practices and Policies: Managers and Employees

33. Oludayo O, Gberevbie, D. E., \& Popoola, D. (2015) A study of multiple work-life balance initiatives in banking industry in Nigeria. International Research Journal of Finance and Economics. 133,108-109.

34. Redmond, J., Valiulis, M., \& Drew, E. (2006) Literature review of issues related to work-life balance, workplace culture and maternity/childcare issues. Crisis Pregnancy Agency: Summary Report of the Consultation for the Strategy to Address the Issue of Crisis Pregnancy. http://doi.crisispregnancy.ie/pub/Rep3.pdf

35. Russell, H., O'Connell, P.J., \& McGinnity, F. (2009). "The Impact of Flexible Working

36. Sakthivel, R., Kamalanabhanb \& Selvarania. (2011) Work life balance reflections on employee satisfaction. Serbian Journal of Management, 6 (1) 85 - 96

37. Sheppard, G. (2016). Work-life balance programs to improve employee performance. A Doctoral Thesis Presented to Walden University.

38. Thevanes, N., \& Mangaleswaran, T. (2018). Relationship between work life balance and job performance of employees. IOSR Journal of Business and Management (IOSR-JBM), 20(5), 1116.

39. Torrington, D., Taylor, S., Hall, L \& Atkinson, $C$. (2011). Human resource management (8th ed). London: Prentice Hall. London: Prentice Hall

40. Upadhaya, B, Munir, $R$ \& Blount, Y. (2014). Association between performance measurement systems and organizational effectiveness. International Journal of Operations and Production Management, 34(7), 853-875.

41. Vishwa N. M., Chandra K., Jaggi, Bijay .S, Charanjeet .S., Avadhesh K. M., \& Diwinder. K., (2015) Empirical analysis of work life balance policies and its impact on employee's job satisfaction and performance: Descriptive statistical approach. American Journal of Theoretical and Applied Statistics. 4(2), 33-43.

42. Walter, J. \& Walters, J. (2010). Positive management: Increasing employee productivity. New York, USA: Business Expert Press, LLC. 